\title{
Ultracytochemistry of Mouse Subcutaneous Histiocytes
}

\section{Processes of the Horseradish Peroxidase Uptake ${ }^{1,2}$}

\author{
Hiroshi Mayahara ${ }^{3}$ \\ Department of Anatomy (Supervized by Prof. Kazuo Ogawa), \\ Kansai Medical School, Moriguchi, Osaka, 570, Japan
}

\section{INTRODUCTION}

Subcutaneous histiocytes (fixed macrophages) are normal resicients in the srkcterects loose connective tissue. Since the fact that histiocytes have high phagccytotic activity and constitute a part of the reticuloendothelial system was established (Kiyono, 1919 ; Aschoff, 1924), extensive works concerning histiocytes have been performed (see the recent review by Pearsall and Weiser, 1970). However, the ultrastructural investigations of histiocytes are rather scanty (Tanaka, 1958; Kajikawa and Hirono, 1960 ; Ross and Benditt, 1962 ; Sato, 1965 ; Kajikawa et al., 1970), and there have been practically no ultracytochemical studies of histiocytes as yet.

Since the original reports of Graham and Karnovsky (1966a, b) who introduced the horseradish peroxidase as a tracer of exogenous protein in electron microscopy, quite an amount of works using exogenous peroxidase as a tracer have been published. Many of these are, however, the works on tracing the peroxidase injected intravascularly (Becker et al., 1967 ; Brightman, 1967 ; Karnovsky, 1967 ; Reese and Karnovsky, 1967 ; Sommer and Johnson, 1968 ; Becker and Almazon, 1968 ; Bodenheimer and Brightman, 1968 ; Graham and Kellermeyer, 1968 ; Holtzman and Dominitz, 1968 ; Hugon and Borgers, 1968 ; Schneeberger-Keely and Karnovsky, 1968 ; Clementi and Palade, 1969 ; Graham et al., 1969 ; Holtzman and Peterson, 1969 ; Forssmann and Girardier, 1970 ; Like, 1970 ; Fahimi, 1970

1. A part of this work has been presented at the 25th Scientific Meeting of the Japanese Society of Electron Microscopy held in Tokyo on May 10-11, 1969 (J. Elect. Micro., 18, 224, 1969) and at the US-Japan Seminar held in Oiso on August 28-31, 1972 (Acta Histochem. Cytochem., 4, in press).

2. This is a partial requirement for the fulfilment of the degree of the Doctor of Philosophy in Biology.

3. Present address : Laboratory of Developmental Biology, Zoological Institute, Faculty of Science, University of Kyoto, Kyoto, 606, Japan 
; Jewett et al., 1971; Schneeberger and Karnovsky, 1971). Some works tracing the peroxidase injected extravascularly or the peroxidase challenged in vitro have been published (Collins, 1967 ; Friend and Farquhar, 1967 ; Locke and Collins, 1968 ; Cotran and Karnovsky, 1968 ; Seder, 1969 ; Zacks and Saito, 1969 ; Watanabe et al., 1969 ; Holtzman et al., 1970 ; Cotran and Litt, 1970 ; Peyman et al., 1970). However, no works have been published on the mode of exogenous peroxidase uptake injected subcutaneously.

In the present study, the mode of exogenous peroxidase uptake and the reactive changes of the lysosomal system accompanying with uptake are investigated in the mouse subcutaneous histiocytes using ultrastructural and ultracytochemical technics.

\section{MATERIAL AND METHODS}

\section{Material}

Male DD mice, weighing 25 to $30 \mathrm{gm}$ were used. They were fed with stock laboratory chow NMF (Oriental Yeast Ind. Co., Ltd.) ad libitum and were provided with water at all times.

Injection of $0.05 \mathrm{ml}$ of $1 \%$ horseradish peroxidase (crude or Type II, Sigma Chemical Co., St. Louis) dissolved in saline was made subcutaneously in the lower abdominal region of mice. In some cases, peroxidase was dissolved in Freund's incomplete adjuvant. At time intervals of $1,3,5,7,10,15,20$ and $30 \mathrm{~min} ., 1,2,4,8$ and 12 hours, and $1,2,3,4,6,10$ and 14 days after the injection, the animals were sacrificed and subcutaneous tissues excised were used for various investigations described below. The tissue blocks included not only the subcutaneous tissue but also the epidermis and subdermal muscular tissue in order to ascertain the relationship of the injection site to the surrounding tissues. Intact subcutaneous tissues and tissues from mice injected with only saline or adjuvant were used for controls.

In some cases, mice were injected with the same amount of $1 \%$ peroxidase or $1 \%$ ovalbumin two days after the initial peroxidase injection. Mice were sacrificed at 10,20 and 30 minutes after the second injection, and tissues excised were used for investigation.

\section{Methods}

\section{Ultrastructural studies (routine morphology):}

Specimens were fixed in a mixture of formaldehyde-glutaraldehyde (Karnovsky, 1965) for 3 to 5 hours at room temperature. In some cases $\mathrm{CaCl}_{2}$ and $\mathrm{MgCl}_{2}$ (in the final concentration of $0.01 \%$ respectively) were added in the fixative (Ashhurst, 1965). After washing overnight in $0.1 \mathrm{M}$ cacodylate buffer containing $8 \%$ sucrose, specimens were 


$$
S-76
$$

postfixed with $1 \% \mathrm{OsO}_{4}$ in Veronal-acetate buffer, $\mathrm{pH} 7.4$, for 1 hour (Caulfield, 1957), dehydrated in graded ethanols and embedded in Epon (Luft, 1961). Thin sections were cut with glass or diamond knives on a LKB ultratome, mounted directly on 300 or 400-mesh grids, and stained with uranyl acetate and/or lead citrate (Reynolds, 1963). Electron micrographs were taken at magnifications of 2,500 to 30,000 with a JEM-7 electron microscope. For the light microscopic observation, sections of $1 \mu$ thick were cut from Epon blocks, affixed to glass slides by moderate heating and stained with $1 \%$ toluidlne blue in $0.05 \mathrm{M}$ phosphate buffer, $\mathrm{pH}$ 7.0.

\section{Ultracytochemical studies :}

Demonstration of the peroxidase activity: Specimens fixed in Karnovsky's fixative for 3 to 5 hours at room temperature were washed overnight in $0.1 \mathrm{M}$ cacodylate buffer containing $8 \%$ sucrose and frozen sections (40 $\mu$ in thickness) were cut by an electrofreezing microtome (Yamato Koki $C_{0}$.). In some cases, 40-50 $\mu$ non-frozen sections were cut by KO-III Automirochopper (Ogawa et al, . 1966), TC-2 Tissue Sectioner (Smith and Farquhar, 1965) or Vibratome (Oxford Lab., U.S.A.). Sections were incubated in the incubation medium (Graham and Karnovsky, 1966a, b) for $25 \mathrm{~min}$. at room temperature. After incubation, sections were rinsed three times in distilled water, postfixed with buffered $\mathrm{OsO}_{4}$ for 1 hour, and processed for electron microscopy. Occasionally reacted sections were investigated under the light microscope.

Demonstration of the acid phosphatase activity: Frozen or non-frozen sections from tissues fixed in Karnovsky's fixative for 1 hour at $0-4{ }^{\circ} \mathrm{C}$ were incubated in the Gomori type incubation medium (Gomori, 1952) for 20 to $40 \mathrm{~min}$. at $37^{\circ} \mathrm{C}$. After the incubation, sections were directly postfixed in buffered $\mathrm{OsO}_{4}$ and processed for electron microscopy. For the light microscopic observation $20 \mu$ sections incubated in the medium were rinsed briefly in distilled water, treated with $1 \% \mathrm{NH}_{4} \mathrm{HS}$ and mounted in glycerin-jelly.

Ruthenium red staining: Unfixed, small diced specimens were fixed 1 hour in cold $1.2 \%$ glutaraldehyde containing $500 \mathrm{ppm}$ ruthenium red (Luft, 1966) in $0.1 \mathrm{M}$ cacodylate buffer, and postfixed in buffered $\mathrm{OsO}_{4}$ containing $500 \mathrm{ppm}$ ruthenium red for 3 hours at room temperature. In some cases, specimens prefixed in $2 \%$ glutaraldehyde in cacodylate buffer ( $\mathrm{pH}$ 7.4) for 1 hour at $4^{\circ} \mathrm{C}$ were similarly treated as described above in order to compare the staining properties of the prefixed tissues with that of the fresh unfixed tissues. After the postfixation, specimens were processed for electron microscopy.

\section{RESULTS}

\section{Normal histiocytes}

The shape of normal histiocytes are variable but are usually spindle-shaped (Figs. 1-3). 
They reside among the connective tissue fibers and possess many long pseudopodia and deep cytoplasmic invaginations of various sizes (Figs. 1-4). The invaginations have relatively constant width (ca. $400 \mathrm{~A}$ ), but have various length, and sometimes it is as long as 1 to $2 \mu$.

In the cytoplasm, the rough endoplasmic reticulum is relatively scarce (Figs. 1 and 2), and by this character one can easily distinguish histiocytes $(\mathrm{H})$ from fibroblasts $(\mathrm{F})$ (Fig .1). There are also phagosomes (P), coated vesicles (CV) and lysosomes (L) in normal histiocytes (Figs. 1-4). There are tubular structures (T) having ca. $400 \mathrm{~A}$ in width and occasionally they are connected with phagosomes (Fig. 2).

There are no structures showing the endogenous peroxidase activity in normal histiocytes. The acid phosphatase activity was detected in lysosomes and occasionally in the Golgi apparatus, however, detailed results will be described in the second part of the present paper.

By the ruthenium red staining, the plasma membrane, its invagination, forming coated vesicles and forming phagosomes were stained (Figs. 3 and 4 ).

\section{Histiocy tes atter the peroxidase injection}

The reaction products showing the exogenous peroxidase activity detected by the GrahamKarnovsky's method have sufficient electron density to be differentiated from other subcellular elements (Figs. 5-12). There was no appreciable difference in ultracytochemical findings obtained between the case of peroxidase dissolved in saline (Figs. 5-10) and that of peroxidase dissolved in Freund's incomplete adjuvant (Figs. 11 and 12).

No peroxidase activity was detected in those histiocytes injected with saline or adjuvant only.

Early phase ( 1 to 30 minutes after the injection): Within several to 10 minutes after the peroxidase injection, most histiocytes at the site of injection change their form suddenly from the spindle-shape to the spherical one (Figs. 6-10). Their plasma membrane still retains pseudopodia and undulations, but the invaginations found in normal histiocytes disappear almost completely (Figs. 5-15).

The cytoplasm is filled with numerous coated vesicles (C), large or small phagosomes (P) and tubular structures (T) showing the high endocytotic activity of histiocytes.

The peroxidase can be found distributed scatteredly among various cellular as well as fibrous elements. The peroxidase can also be found adsorbed on the plasma membrane of histiocytes (Figs. 5-8). Intracellularly, peroxidase is found in phagosomes (Figs. 5-12), in coated vesicles (Figs. 5-12), in tubular structures (Figs. 11, 16 and 17) and in lysosomes or phagolysosomes (Figs. 7, 8, 11, 16 and 17). 
Phagosomes are formed from invaginations of the plasma membrane. Their size is variable, but always larger than coated vesicles (Figs. 5-12). The size of the largest phagosomes reaches 2 to $3 \mu$ (Fig. 7). At the early phase of peroxidase uptake (10 to 30 minutes after the injection), fusion of small or medium sized phagosomes resulting in the formation of large phagosomes is frequently observed (Fig. 17). Fusion of phagosomes with coated vesicles (Fig. 17), with lysosomes (Figs. 10, 12, 13 and 14) or with tubular structures (Figs, 16 and 17) are also observed.

Coated vesicles are formed from invaginations of the plasma membrane (Figs. 5-12, 16 and 17). They have the mean inner diameter of $1,230 \pm 135 \mathrm{~A}$. In the deeper portion of the cytoplasm many vesicles with peroxidase are found, but the diameter of these vesicles is smaller $(870 \pm 205 \mathrm{~A})$ than that of the usual coated vesicles (Fig. 17). Such vesicles have no coatings. In Fig. 17, a series of vesicles are found. Of such vesicles the larger "coated" ones are near the plasma membrane and the smaller vesicles having no coatings are in the interior portions of the cell. It is not unlikely that as coated vesicles move toward the interior of the cytoplasm, they lose their bristle coatings (ex-coated vesicles) and become smaller in size, and their contents are condensed during this process. Some ex-coated vesicles are elipsoid in shape (long axis : 1,210 $\pm 236 \mathrm{~A}$; short axis : $830 \pm$ $153 \mathrm{~A}$, in average).

Coated vesicles (or more precisely ex-coated vesicles) fuse with phagosomes (Fig. 17), lysosomes (Fig. 11) or phagolysosomes (Figs. 7 and 8). The possibility that small excoated vesieles are absorbed into the cytoplasmic matrix without fusing with any phagosomes and/or lysosomes is unresolved.

When coated vesicles fuse with phagosomes (or lysosomes), there seem to be two modes of fusion. Firstiy, their limiting membranes show the distinct connection with the limiting membrane of phagosomes (or lysosomes) and subsequently only the internal contents are extruded into the interior of the phagosomes (or lysosomes) (Figs. 8 and 11). Secondly, whole ex-coated vesicles with their intact limiting membranes are "thrown" into the interior of phagosomes (or lysosomes) (Figs. 6, 7, 14 and 17).

The tubular structures are ca. $400 \mathrm{~A}$ in width and variable in length, larger ones reaching about $0.5 \mu$. Occasionally, these structures have "bristle coatings" similar to" that of coated vesicles, and have connection with the plasma membrane (Fig. 18); they seem to be formed from invaginations of plasma membrane like phagosomes or coated vesicles. These structures also fuse with phagosomes or phagolysosomes (Figs. 2, 16 and 17).

Fusion of peroxidase positive phagosomes with lysosomes resulting in the formation of 
phagolysosomes is frequently observed at 10 to 30 minutes after the peroxidase injection (Figs. 9, 10 and 12). The pattern of the fusion of phagosomes with lysosomes is uniform ; The limiting membranes of the both organellae are broken at the point of contact, and the broken ends of the limiting membranes curl into the phagosomes (not into the lysosomes), and the contents of the lysosomes are "injected" into the phagosomes (Figs. 10, 12 and 13). The same pattern can be observed when phagosomes fuse with phagolysosomes (Fig. 14).

Thirty minutes after the peroxidase injection, the cytoplasm of histiocytes are occupied with many large phagolysosomes resulted from such frequeut fusion of lysosomes with phagosomes, coated vesicles and/or tubular structures (Fig. 18). The interior of phagolysosomes is filled with vesicular or membranous residues and show high acid phosphatase activity.

Later phase (1 hour to 14 days): The histiocytes which are generally round in shape 30 minutes after the peroxidase injection subsequently change their shape gradually into the original spindle-shape during the course of 14 days (Figs. 21-26). The size of phagolysosomes also decreases gradually. Concomitantly the gradual decrease in both the peroxidase and acid phosphatase activity in them takes place which may show the "digestion" of incorporated exogenous peroxidase.

At 2 hours after injection, the size and the acid phosphatase activity of phagolysosomes show some decrease, and the granularity in them also decrease as compared with those of 30 minutes after the injection (Fig. 20).

At 8 hours after injection, phagolysosomes show different intensity of acid phosphatase activity; some phagolysosomes lose their acid phosphatase activity almost completely and are filled with fibrous materials, whereas others show quite high enzymatic activity (Fig. 21). Some lysosomes are in the course of residual body formation (an arrow in Fig. 21).

The peroxidase activity can be found in a majority of phagolysosomes (or telolysosomes) at 24 or 48 hours after the injection (Figs. 22 and 23). Even 6 or 14 days after the injection, the peroxidase activity is observed occasionally in some residual body type lysosomes (Figs. 24 and 25). However, most histiocytes show close resemblance to normal histiocytes at 14 days after the injection; they are spindle-shaped and have many relatively small lysosomes, some of which are acid phosphatase positive, but others negative (Fig. 26).

\section{The tate of telolysosomes}

The fate of telolysosomes (or lysosomes once had passed the stage of phagolysosomes) 
was investigated by injecting peroxidase or ovalbumin 2 days after the initial peroxidase injection. At this time (2 days afer the initial injection), phagolysosomes are changing to telolysosomes losing gradually their acid phosphatase activity, but the exogenons peroxidase activity is still preserved in a majority of phagolysosomes (or telolysosomes) as described above, that is to say, phagolysosomes (or telolysosomes) are "labeled" with peroxidase injected two days ago. The second injection proved that new phagolysosomes are formed from pre-existing "peroxidase-labeled" lysosomes (Fig. 27). Thus, it is indicated that telolysosomes may have the ability to be reactivated to function as primary lysosomes when foreign materials are injected again.

\section{DISCUSSION}

\section{Identification of histiocytes}

The main cellular residents in the normal mouse subcutaneous connective tissue are fibroblasts and histiocytes (fixed macrophages). In addition, mast cells, acidophil leucocytes and cells composing blood vessels are found occasionally. Sato (1965) stated that three cell types are identified in the rabbit subcutaneous connective tissue, that is, fibroblasts, fixed histiocytes and free histiocytes, and that there was some difficulty in distinguishing between fibroblasts and fixed histiocytes. In the mouse subcutaneous tissue, histiocytes are easily distinguished from fibroblasts by their scarcity of the rough endoplasmic reticulum and abundance in vesicles and lysosomes of various types (Fig. 1). There are no organellae showing the endogenous peroxidase activity in normal histiocytes. The same results have been reported by the light microscopic study of rabbit histiocytes (Akasaki and Kozima, 1963).

\section{Ultrastructure of histiocytes}

Normal histiocytes have abundant long pseudopodia and deep invaginations. These long pseudopodia and invaginations disappear almost completely at 10 minutes after the peroxidase injection, and the process of disappearance of these structures may be interpreted as follows. When active endocytosis is induced by the peroxidase injection, excessive plasma membrane will be needed for two reasons; firstly, the plasma membrane is consumed in large quantity by forming numerous pinocytotic vesicles, since they are formed by pinching off of the plasma membrane, and secondly, as the results of such active phagocytosis, the volume of histiocytes will inevitably increase, and accordingly more surface area will be needed. These long pseudopodia and deep invaginations seem to function as the "spare" of the plasma membrane, and the high endocytotic activity of histiocytes may be supported at least partly by these structures. The presence of such 
"spare" plasma membrane was reported also on the transitional epithelial cells which can remarkably change their shape in short period depending on their physiological state (Hicks, 1966 ; Koss, 1969).

\section{Ruthenium red staining}

Kajikawa et al. (1970) reported that coated vesicles of histiocytes were ruthenium red (RR)-positive when rat subcutaneous tissues were stained. They found RR-negative vesicles among the RR-positive coated vesicles and assumed that these unstained vesicles might represent "exocytosis". However, when "closed" intracellular vesicles having no direct connection to the exterior of the cell are stained with RR, either of the following two conditions must be satisfied : a) RR must penetrate both the plasma membrane and the limiting membrane of the vesicles or b) $R R$ must be incorporated into the vesicles by phagocytosis occuring in the fixative containing $R R$. The first case is not plausible because RR can not penetrate across the plasma membrane (Luft, 1966; Yamamoto, 1971). The latter case is also unplausible because it is unreasonable to assume that histiocytes have the phagocytotic activity in the fixative containing $1.2 \%$ glutaraldehyde and kept at $0-4{ }^{\circ} \mathrm{C}$. To certify whether the staining of vesicles such as coated vesicles or phagosomes is due to the active phagocytosis in the cold fixatives containing RR or not, an attempt was made to stain the prefixed specimens having no phagocytotic activity and compare their staining properties with that of the fresh specimens. It was observed that the staining properties of the prefixed histiocytes were just the same as that in the fresh histiocytes (Fig. 15), that is, the possibility of phagocytosis was denied. RR stains only external coat of the surface plasma membrane. Thus, it should be considered that the RRpositive "vesicles" are in reality continuous with the exterior of the cell. The description by Kajikawa et al. that "coated vesicles are stained with RR" has to be revised as "forming coated vesicles are stained with RR".

\section{Mode of exogenous peroxidase uptake}

It was revealed that there are three different routes of peroxidase uptake; via phagosomes, coated vesicles and tubular structures. The problem in question is whether any functional differences exist among these routes.

The coated vesicles are of great interest because of their peculiar bristle coatings, subsequent loss of coatings and diminishing of their size accompanied by the condensation of the contents. The loss of bristle coatings has been reported in other cells (Roth and Porter, 1964 ; Bruni and Porter, 1965 ; Friend and Farquhar, 1967), however, the diminishing of their size and condensation of the contents have not been reported yet. Kanaseki (1969) investigated the three-dimensional ultrastructure of coated vesicles and stated 
that the coating has a basket-like ultrastructure and that this "basket" may be made of contractile protein and by its contraction the plasma membrane is pinched off and coated vesicles are formed. However, as phagosomes or micropinocytotic vesicles found in capillary endothelium or muscle cells seem to have no such apparatus for pinching off, it is strange to speculate that only the coated vesicles need such apparatus for pinching off.

There have been many reports stating that coated vesicles are engaged in uptake of more or less specific proteins (Telfer, 1960 ; Roth and Porter, 1964 ; Anderson, 1964 ; Bowers, 1964 ; Maunsbach, 1966 ; Friend and Farquhar, 1967 ; Hugon and Borgers, 1968 ; Holtzman and Peterson, 1969). The coat of the coated vesicles may have some relation to the specificity of the incorporation. In addition, Schjeide (1970) recently reported the presence of DNA in the isolated coated vesicle fraction. These findings propose the urgent necessity of the more detailed elucidation of the structure and the function of the coated vesicles.

The presence of the tubular structures was revealed in histiocytes during the peroxidase uptake. The uptake of foreign materials in such tubular structures has been reported in cells of renal proximal convoluted tubules (Graham and Karnovsky, 1966 a), adrenal medullaly cells (Holtzman and Dominitz, 1968), Langerhans cells of the skin (Cancilla, 1968), gastric acid-secreting cells (Sedar, 1969), neurons (Holtzman and Peterson, 1969), hepatic parenchymal cells (Graham et al., 1969) and $\beta$-cells of the islet of Langerhans (Like, 1970).

\section{Phagolysosomes}

Fusion of phagosomes with pre-existing lysosomes has been suspected already at the light microscopic level (Straus, 1964) and has been proved in some cells electron microscopically also (Zucker-Franklin and Hirsh, 1964 ; Hirsh and Cohn, 1964 ; Ericsson, 1964 ; Gordon et al., 1965 ; Brandes and Anton, 1969). The present investigation also confirmed the finding in histiocytes. It should be emphasized that although the fusion of phagosomes with nearby lysosomes may not be evident in one section, they may well be fusing in other section in serial sections (Figs. 9 and 10). When lysosomes and phagosomes fuse with each other, there is a definite tendency of the mode of the fusion of membranes. The direction of the curling of the broken ends of the both limiting membranes is from the side of lysosomes to the side of phagosomes and never in the reverse direction (Figs. 10, 12,13 and 14), though the reason for which is unknown.

The peroxidase activity was found in some residual body type lysosomes even 6 or 14 days after injection. It has also been reported that some original properties of exogenous 
protein such as antigenicity, enzyme activity and radioactivity are well preserved in macrophages over a few or several days (Straus, 1962 ; Ehrenreich and Cohn, 1968 ; Unanue and Askonas, 1968). The result of the present study, that is, the preservation of the enzyme activity for 14 days, seems to be one of the longest examples of such preservation. The long term preservation of the original properties of the exogenous protein in macrophages may be noteworthy in relation to the antibody formation.

\section{The "life cycle" in the lysosomal system}

The phagolysosomes tend to become gradually smailer at and after 2 hours following the peroxidase injection. Some of them seem to become residual body like lysosomes (Fig. 25) having granular appearance, and most of them seem to become telolysosomes resembling original lysosomes of intact histiocytes (Fig. 26). Could such residual body type lysosomes or telolysosomes be reactivated by an another injection of foreign materials ? If so, there is a possibility of the presence of the cycle from primary lysosomes to phagolysosomes, phagolysosomes to telolysosomes and telolysosomes again to primary lysosomes, namely, the "life cycle" in the lysosomal system. To demonstrate such cycle, an attempt was made to inject exogenous proteins (peroxidase or ovalbumin) again two days after the initial peroxidase injection (at this time lysosomes are still peroxidase positive, i.e. lysosomes are "labeled" with peroxidase injected two days ago). The results of the second injection strongly suggest the presence of such "life cycle" in the lysosomal system, that is, new phagolysosomes were formed from the pre-existing "peroxidaselabeled" lysosomes (Fig. 27). The presence of such cycle in the lysosomal system has been suspected by some investigators (Gordon et al., 1965 ; Maunsbach, 1969), however, the convincing evidence $e^{-}$was obtained for the first time in the present study.

\section{SUMMARY}

The process of horseradish peroxidase uptake and the accompanying reactive changes of the lysosomal system were investigated in mouse histiocytes by ultracytochemical methods.

Mice were injected subcutaneously with horseradish peroxidase, and at time intervals ranging from 1 minute to 14 days after the injection mice were sacrificed and tissues were used for the demonstration of both the peroxidase activity (the marker of the exogenous protein) and the acid phosphatase activity (the marker of the lysosomal system) at the electron microscopic level.

Within several minutes after injection, the original spindle-shaped histiocytes change to spherical, and their cytoplasm are filled with numerous endocytotic vesicles. The exogenous 
peroxidase is incorporated into the histiocytes via phagosomes, coated vesicles and tubular structures. These organellae fuse eventually with pre-existing lysosomes resulting in the formation of phagolysosomes, that is to say, exogenous peroxidase is delivered to the Iysosomal system and digested there. Subsequently, both histiocytes and lysosomes in them show resemblance to their original shape. However, the peroxidase activity is found in some residual body type lysosomes even 6 to 14 days after injection.

The second injection of the exogenous proteins gave rise to the formation of new phagolysosomes from the pre-existing lysosomes "labeled" with the peroxidase injected 2 days ago. This result strongly suggests the presence of the "life cycle" in the lysosomal system in histiocytes.

\section{ACKNOWLEDGMENT}

The author is very grateful to Prof. Kazuo Ogawa for his advice and encouragement during the course of the present study, and also for his helpful criticism of the manuscript. The author is also grateful to Miss T. Kobayashi, Miss T. Izumi, Miss R. Eguchi and Mr. Y. Furusawa for their helpful assistance.

\section{REFERENCES}

1) Akasaki, K. and Kojima, M. : Molphology and function of reticulo-endothelial system. In "The Complete Works of Hematology in Japan. Vol. I. Molphology". ed. by S. Amano et al., Maruzen Co., Tokyo, 645-672, 1963 (in Japanese).

2) Anderson, E. : Oocyte differentiation and vitellogenesis in the roach Periplaneta americana J. Cell Biol., 20, 131-155, 1964.

3) Ashhurst, D. E. : Mitochondrial particles seen in sections. J. Cell Biol., 24, 497-499, 1965.

4) Aschoff, L. : Das reticulo-endotheliale System. Ergebn. inn. Med., 26, 1-118, 1924.

5) Becker, N. H, and Almazon, R. : Evidence for the functional polarization of micropinocytotic vesicles in the rat choroid plaxus. J. Histochem. Cytochem., 16, 278-280, 1968.

6) Becker, N. H., Novikoff, A.B. and Zimmerman, H.M. : Fine structure observations of the uptake of intravenously injected peroxidase by the rat choroid plexus. J. Histochem. Cytochem., 15, 160-165, 1967.

7) Bodenheimer, T.S. and Brightman, M.W. : A blood-brain barrier to peroxidase in capillaries surrounded by perivascular spaces. Amer. J. Anat., 122, 249-268, 1968.

8) Bowers, B. : Coated vesicles in the pericardial cells of the aphid (Myzus persecae Sulz). Protoplasma, 59, 351-367, 1964.

9) Brandes, D. and Anton, E. : An electron microscopic cytochemical study of macrophages during uterine involution. J. Cə̉ll Biol., 41, 450-461, 1969.

10) Brightman, M.W. : The intracerebral movement of proteins injected into blood and cerebrospinal fluid of mice. Progr. Brain Res., 29, 19-37, 1967.

11) Bruni, C. and Porter, K. R. : The fine structure of the parenchymal cell of the normal rat liver. I. General observations. Amer. J. Path., 46, 691-755, 1965. 
12) Cancilla, P. A. : Demonstration of the Langerhans granule by lanthanum. J. Cell Biol., 38, 248-252, 1968.

13) Caulfield, J.B. : Effects of varying the vehicle for $\mathrm{OsO}_{4}$ in tissue fixation. J. Biophys. Biochem. Cytol., 3, 827-830, 1957.

14) Clementi, F. and Palade, G. E. : Intestinal capillaries. I. Permeabiliy to peroxidase and ferritin. J. Cell Biol., 41, 33-58, 1969.

15) Collins, J. V. : Protein uptake in multivesicular bodies in the molt-intermolt cycle of an insect. Science, 155, 467-469, 1967.

16) Cotran, R.S. and Karnovsky, M.J. : Ultrastructural studies on the permeability of the mesothelium to horseradish peroxidase. J. Cell Biol., 37, 123-137, 1968.

17) Cotran, R.S. and Litt, M. : Ultrastructural localization of horseradish peroxidase and endogenous peroxidase activity in ginea pig peritoneal macrophages. J. Immunol., 105, 1536-1546, 1970.

18) Ehrenreich, B. A. and Cohn, Z.A. : Fate of hemoglobin pinocytosed by macrophages in vitro. J. Cell Biol., 38, 244-248, 1968.

19) Ericsson, J.L. : Absorption and decomposition of homologous hemoglobin in renal proximal tubular cells. Acta Path. Microbiol. Scand. (Supp.), 168, 1-121, 1964.

20) Fahimi, H.D. : The fine structural localization of endogenous and exogenous peroxidase activity in Kupffer cells of rat liver. J. Cell Biol., 47, 247-262, 1970.

21) Forssmann, W. G. and Girardier, L. : A study of the T-system in rat heart. J. Cell Biol., 44, 1-19, 1970.

22) Friend, D. S. and Farquhar, M. G. : Functions of coated vesicles during protein absorption in the rat vas deferens. J. Cell Biol., 35, 357-376, 1967.

23) Gomori, G. : "Microscopic Histochemistry. Principles and Practice". Univ. Chicago Press, Chicago, 1952.

24) Gordon, G. B., Miller, L. R. and Bensch, K. G. : Studies on the intracellular digestive process in mammalian tissue culture cells. J. Cell Biol., 25, 41-55, 1965.

25) Graham, R.C. and Karnovsky, M. J. : The early stages on absorption of injected horseradish peroxidase in the proximal tubules of mouse kidney: Ultrastructural cytochemistry by a new technique. J. Histochem. Cytochem., 14, 291-302, 1966a.

26) Graham, R.C. and Karnovsky, M. J. : Glomerular permeability. Ultrastructural cytochemical studies using peroxidase as protein tracers. J. Exp. Med., 124, 1123-1134, 1966b.

27) Graham, R.C. and Kellermeyer, R.W. : Bovine lactoperoxidase as a cytochemical protein tracer for electron microscopy. J. Histochem. Cytochem., 16, 275-278, 1968.

28) Graham, R.C.,Limpert, S. and Kellermeyer, R.W. : The uptake and transport of exogenous proteins in mouse liver. Lab. Invest., 20, 298-304, 1969.

29) Hicks, R. M. : The function of the Colgi complex in transitional epithelium. Synthes is of the thick cell membrane. J. Cell Biol., 30, 623-643, 1966.

30) Hirsh, J. G. and Cohn, Z. A. : Digestive and autolytic functions of lysosomes in phagocytic cells. Fed. Proc., 23, 1023-1025, 1964.

31) Holtzman, E. and Dominitz, R. : Cytochemical studies of lysosomes, Golgi apparatus and endoplasmic reticulum in secretion and protein uptake by adrenal medulla cells of the rat. J. Histochem. Cytochem., 16, 320-336, 1968.

32) Holtzman, E. Freeman, A. R. and Kashner, L. A. : A cytochemical and electron microscope study of channels in the Schwann cells surrounding lobster giant axons. J. Cell Biol., 44,

Supplement to J. Kansai Med. Sch., Vơl. 24, March 1972 
$S-86$

438-445, 1970.

33) Holtzman, E. and Peterson, E. R. : Uptake of protein by mammalian neurons. J. Cell Biol., 40, 863-869, 1969.

34) Hugon, J. S. and Borgers, M. : Absorption of horseradish peroxidase by the mucosal cells of the duodenum of mouse. I. The fasting animal. J. Histochem. Cytochem., 19, 229-236, 1968.

35) Jewett, P. H., Sommer, J. R. and Johnson, E. A. : Cardiac muscle. Its ultrastructure in the finch and humming bird with special reference to the sarcoplasmie reticulum. J. Cell Biol., 49, 50-65, 1971.

36) Kajikawa, $\mathbf{K}$. and Hirono, R. : A characteristic granular component of histiocytes of the mouse skin. J. Elect. Micro., 8, 50-54, 1960.

37) Kajikawa, K., Nakanishi, I., Hori, I., Matsuda, Y. and Kondo, K. : Electorn microscopic observations on connective tissue using ruthenium red staining. J. Elect. Micro., 19, 347 $-354,1970$ (in Japanese).

38) Kanaseki, T. and Kadota, $\mathbf{K}$. : "The vesicle in a basket". A morphological study of the coated vesicle isolated from the nerve endings of the ginea pig brain, with special reference to the mechanism of membrane movement. J. Cell Biol., 42, 202-220, 1969.

39) Karnovsky, M. J. : A formaldehyde-glutaraldehyde fixative of high osmolarity for use in electron microscopy. J. Cell Biol., 27, 137A-138A, 1965.

40) Karnovsky, M. J. : The ultrastructural basis of capillary permeability studied with peroxidase as a tracer. J. Cell Biol., 35, 213-236, 1967.

41) Kiyono, K. : Leucocytes in blood and tissues, with special regard to the histiocytic cell. Jap. J. Pathol., 8, 1-7, 1919 (in Japanese).

42) Koss, L. G. : The asymmetric unit membranes of the epithelium of the urinary bladder of the rat. Lab. Invest., 21, 154-168, 1969.

43) Like, A. A. : The uptake of exogenous peroxidase by the beta cells of the islet of Langerhans. Amer. J. Pathol., 59, 225-246, 1970.

44) Locke, M. and Collins, J. V. : Protein uptake into multivesicular bodies and storage granules in the fat body of an insect. J. Cell Biol., 36, 453-483, 1968.

45) Luft, J. H. : lmprovements in exoxy resin embedding methods. J. Biophys. Biochem. Cytol., 9, 409-414, 1961.

46) Luft, J. H. : Ruthenium red staining of striated muscle cell membrane and the myotendinal junction. In "Electron Microscopy 1966", ed. by R. Ueda, Maruzen Co., Tokyo, vol. II, 65 $-66,1966$.

47) Maunsbach, A. B. : Absorption of $\mathbf{I}^{\mathbf{1 2 5}}$ - labeled homologous albumin by rat kidney proximal tubule cells: A study of micro-perfused single proximal tubules by electron microscopic autoradiography and histochemistry. J. Ultrastruct. Res., 15, 197-241, 1966.

48) Maunsbach, A. B. : Functions of lysosomes in kidney cells. In "Lysosomes in Biology and Pathology", ed. by J. T. Dingle and H. B. Fell, North-Holland Pub. Co., Amsterdam, vol. 1, 116-154, 1969.

49) Ogawa, K., Saito, T., Hirano, H. and Mayahara, H. : An automicrochopper for unfrozen sectioning. An oral presentation at the 7th Anual General Meeting of the Society for Histochemistry and Cytochemistry in Japan, at Chiba, 1966.

50) Pearsall, N. N. and Weiser, R.S. : "The Macrophage". Lea \& Febiger Co., Philadelphia, 
1970.

51) Peyman, G. A., Spitznas, M. and Straatsma, B. R. : Peroxidase diffusion in the normal and photocoagulated retina. Investigative Ophthalmology, 10, 181-189, 1971.

52) Reese, T. S. and Kamovsky, M. J. : Fine structural localization of a blood-brain barrier to exogenous peroxidase. J. Cell Biol., 34, 207-217, 1967.

53) Reynolds, E. S. : The use of lead citrate at high $\mathrm{pH}$ as an electron-opaque stain in electron microscopy. J. Cell Biol., 17, 208-212, 1963.

54) Ross, R. and Benditt, E. P. : Wound healing and collagen formation. II. Fine structure in experimental scurvy. J. Cell Biol., 12, 533-551, 1962.

55) Roth, T. F. and Porter, K. : Yolk protein uptake in the oocyte of the mosquito Aedes aegypti L. J. Cell Biol., 20, 313-332, 1964.

56) Sato, E. : The electron microscopic study of rabbit subcutaneous cells. Jap. J. R. E. S., 5, 213-236, 1965 (in Japanese).

57) Schjeide, O. A. and Lin, R. I. Biomembrane synthesis and assembly. In "Cell Differentiation", ed. by. O. A. Schjeide and J. de Vellis, Van Nostrand Reinhold Co., N. Y., 224262, 1970.

58) Schneeberger-Keeley, E. E. and Karnovsky, M. J. : The ultrastructural bases of alveolarcapillary. Membrane permeability to peroxidase used as a tracer. J. Cell Biol., 37, 781793, 1968.

59) Schneeberger, E. E. and Karnovsky, M. J. : The influence of intravascular fluid volume of the permeability of newborn and adult mouse lungs to ultrastructural protein tracers. J. Cell Biol., 49, 319-334, 1971.

60) Sedar, A. W. : ptake of peroxidase into the smooth-surfaced tubular system of the gastric acid-secreting cell. J. Cell Biol., 43, 179-184, 1969.

61) Smith, R. E. and Farquhar, M. G. : Preparation of nonfrozen sections for electron microscope cytochemistry. RCA Scient. Instr. News, 10, 13-18, 1965.

62) Sommer, J. R, and Johnson, E. A. : Purkinje fibers of the heart examined with the peroxidase reaction. J. Cell Biol., 37, 570-574, 1968.

63) Straus, w. : Colorimetric investigation of the uptake of an intravenously injected protein (horseradish peroxidase) by rat kidney and effects of competition by egg white. J. Cell Biol. , 12, 231-246, 1962.

64) Straus, W. : Cytochemical observation on the relationship between lysosomes and phagosomes in kidney and liver by combined staining for acid phoshatase and intravenously injected horseradish peroxidase. J. Cell Biol., 20, 497-507, 1964.

65) Tanaka, H. : Comparatire cytologic studies by means of an electron microscope on monocytes, subcutaneous histiocytes, reticulum cells in the lymph nodes and peritoneal macrophages. Ann. Report. Inst. Virus Res. Kyoto Univ., Series A, 1, 87-149, 1958.

66) Telfer, W.H. : The selective accumulation of blood proteins by the oocytes of saturniid moths. Biol. Bull., 118, 338-351, 1960.

67) Unanue, E. R. and Askonas, B. A. : Persistence of immunogenicity of antigen after uptake by macrophage. J. Exp. Med., 127, 915-926, 1968.

68) Watanabe, K. Masubuchi, N., Ooya, T., Suzuki, Y. and Kageyama, K. : Macrophage and antibody productions. An immunocytochemical and enzymecytochemical study of lymph nodes. Symposium on Immunobiology, 2, 53-68, 1969 (in Japanese).

69) Yamamoto, T. : Mucopolysaccarides. I. Ruthenium red. In "Development in Electronmicro- 
scopy in the Medical and Biological Fields", Igakuno Ayumi, 76, 315-320, 1971 (in Japanese).

70) Zacks, S. I. and Saito, A. : Uptake of exogenous horseradish peroxidase by coated vesicles in mouse neuromuscular junctions. J. Histochem. Cytochem., 17, 161-170, 1969.

71) Zucker-Franklin, D. and Hirsh, J. G. : Electron microscope studies on the degranulation of rabbit peritoneal leucocytes during phagocytosis. J. Exp. Med., 120, 569-573, 1964.

\section{Explanation of Figures}

Figs. 1-27. Subcutaneous histiocytes from the lower abdomen of adult DD mice.

Fig. 1. From a normal control mouse. Routine morphology. A histiocyte $(H)$ and a fibroblast $(F)$. The histiocyte is spindle-shaped and possesses many pseudopodia and invaginations of the plasma membrane. $\quad \times 6,000$

Fig. 2. Ibid. A part of a histiocyte. There are phagosomes (P), forming coated vesicles (CV), lysosomes (L) and tubular structures (T). An arrow indicates the tubular structure connecting with a phagosome. $\quad \times 27,000$

Figs. 3 and 4. From a normal control mouse. Ruthenium red (RR) staining. The plasma membrane, its deep invaginations (arrows) and vesicles having connection to the exterior of the cells are stained. Fig. $3: \times 17,000$, Fig. $4: \times 15,000$

Figs. 5 and 6. Ten minutes after the peroxidase injection. Peroxidase reacton. The peroxidase is seen adsorbed on the plasma membrane and in coated vesicles and phagosomes. Hereafter, if no remarks are made, peroxidase is dissolved in saline. Fig. 5: $\times 29,000$, Fig. $6: \times 17,000$

Fig. 7. Ibid. Peroxidase can be observed on the plasma membrane, in coated vesicles and in the irregularly shaped lysosomes (arrows).

$\times 19,000$

Fig. 8. Ibid. An arrow shows an ex-coated vesicle just fusing with a phagolysosome. The limiting membrane of the coated vesicle seems to be connected with that of the phagolysosome, and its content (peroxidase) is in the moment of being extruded into the phagolysosome.

$\times 27,000$

Figs. 9 and 10. Ibid. These two photographs are from serial sections. Fusion of a phagosome with a lysosome can be seen. Although the fusion is not clear in Fig. 9, it is evident in Fig. 10 (an arrow). $\times 35,000$

Fig. 11. Ten minutes after the peroxidase injection (dissolved in adjuvant). Peroxidase activity is found in phagosomes $(\mathrm{P})$, coated vesicles (CV), tubular structures $(\mathrm{T})$ and lysosomes $(\mathrm{L}) . \quad \times 20,000$

Fig. 12. Ibid. Fusion of phagosomes contaning peroxidase with lysosomes are clearly observed (arrows). $\quad \times 37,000$

Fig. 13. Ten minutes after the peroxidase injection. Acid phosphatase reaction. A lysosome is just fusing with a phagosome (an arrow). Note the direction of the broken ends of the limiting membrane of the phagosome. $\quad \times 17,000$

Fig. 14. Ibid. A phagolysosome is just fusing with a phagosome (an arrow). Note the direction of the broken ends of the limiting membrane of the phagosome. $\quad \times 16,000$

Fig. 15. Ten minutes after the peroxidase injection. Ruthenium red (RR) staining after prefixation with $2 \%$ glutaraldehyde for 1 hour. The plasma membrane, its invaginations, forming coated vesicle and forming phagosome are stained with RR. These RR-positive 
"vesicles" have direct connection with the exterior of the cell. $\quad \times 28,000$

Figs. 16 and 17. Thirty minutes after the peroxidase injection. Peroxidase reaction. Peroxidase is positive on the plasma membrane and in phagosomes, coated vesicles and tubular structures. In the middle of Fig. 17, there are many ex-coated vesicles in which the loss of bristle coatings as well as the decrease in size are evident as they move toward the interior of the cytoplasm. Fig. $16: \times 16,000$, Fig. $17: \times 27,000$

Fig. 18. Twenty minutes after the second injection of peroxidase two days after the initial peroxidase injection. Peroxidase reaction. The irregulariy shaped lysosome show the peroxidase activity. A tubular structure $(T)$ showing peroxidase activity has direct connection with the plasma membrane suggesting that the structure is of plasma membrane origin. The tubular structure has the bristle coating. $\quad \times 22,000$

Fig. 19. Thirty minutes after the peroxidase injection. Acid phosphatase reaction. There are many large round phagolysosomes showing the high acid phosphatase activity. There are practically neither primary lysosomes nor irregularly shaped lysosomes. $\quad \times 9,000$

Fig. 20. Two hours after the peroxidase injection. Acid phosphatase reaction. Note some loss of both acid phosphatase activity and granularity in phagolysosomes. $\quad \times 13,000$

Fig. 21. Eight hours after the peroxidase injection. Acid phosphatase reaction. Note the variation in the intensity of acid phosphatase activity in phagolysosomes, showing that they are in the stage of residual body (telolysosome) formation (an arrow). In some phagolysosomes the activity is almost completely lost. $\quad \times 15,000$

Fig. 22. One day after the peroxidase injection. Peroxidase reaction. Peroxidase is still preserved in almost all phagolysosomes, but not in coated vesicles. $\quad \times 13,000$

Fig. 23. Two days after the peroxidase injection. Peroxidase reaction. Peroxidase (injected two days ago) is found in a majority of lysosomes. Some lysosomes are irregularly shaped. $\times 31,000$

Fig. 24. Six days after the peroxidase injection. Peroxidase reaction. Peroxidase is still preserved in some residual body type lysosomes. $\quad \times 17,000$

Fig. 25. Fourteen days after the peroxidase injection. Peroxidase reaction. The activity is still preserved in some residual body type lysosomes. $\quad \times 9,000$

Fig. 26. Fourteen days after the peroxidase injection. Acid phosphatase reaction. The overall features of the cell closely resemble the normal untreated histiocyte. $\quad \times 21,000$

Fig. 27. Twenty minutes after the second injection of ovalbumin two days after the initial peroxidase injection. Peroxidase reaction. New phagolysosomes are formed from the pre-existing lysosomes "labeled" with the peroxidase injected two days ago. $\quad \times 18,000$ 


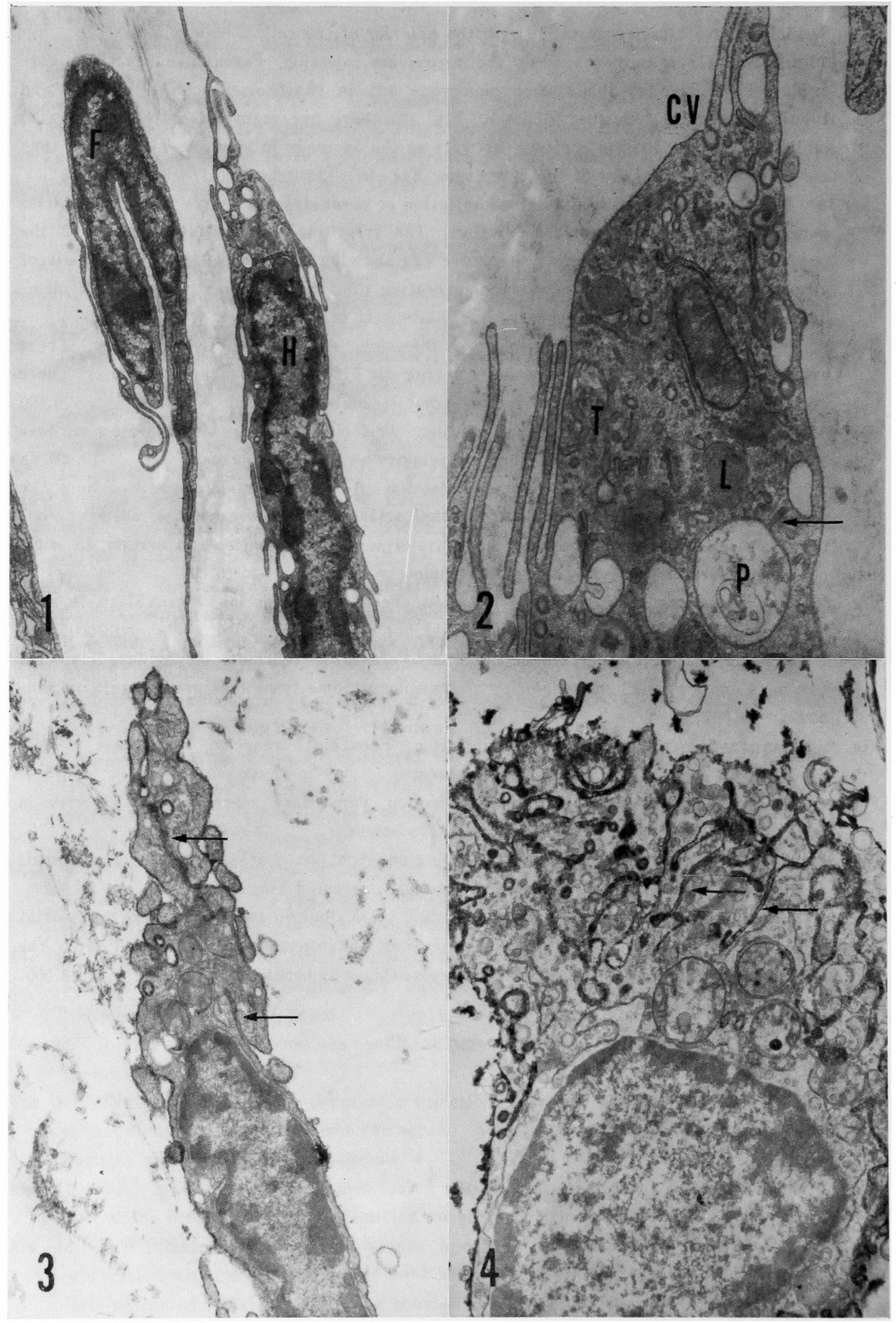




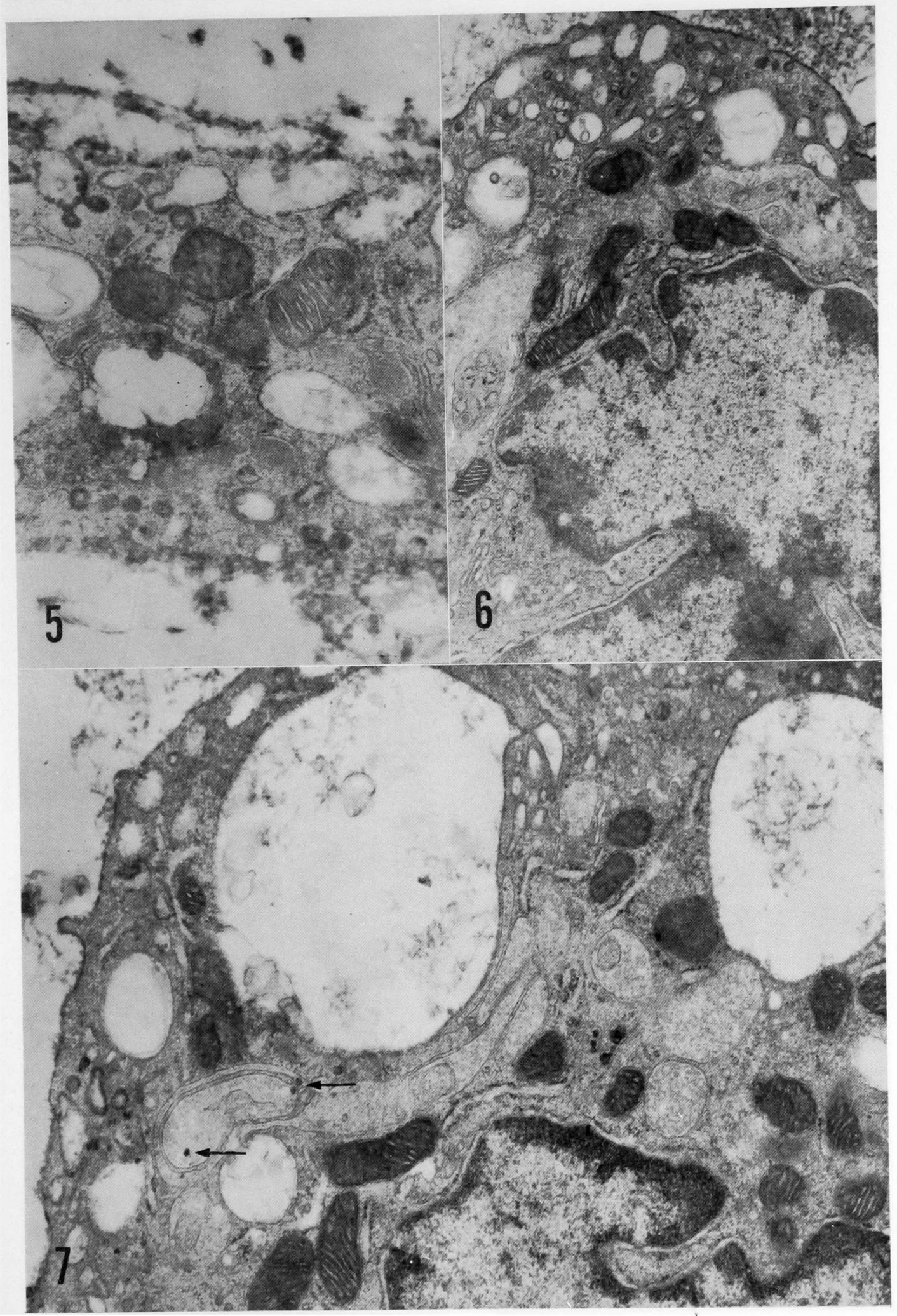

Suthlement to I. Kansai Med. Sch., Vol. 24, March 1972 


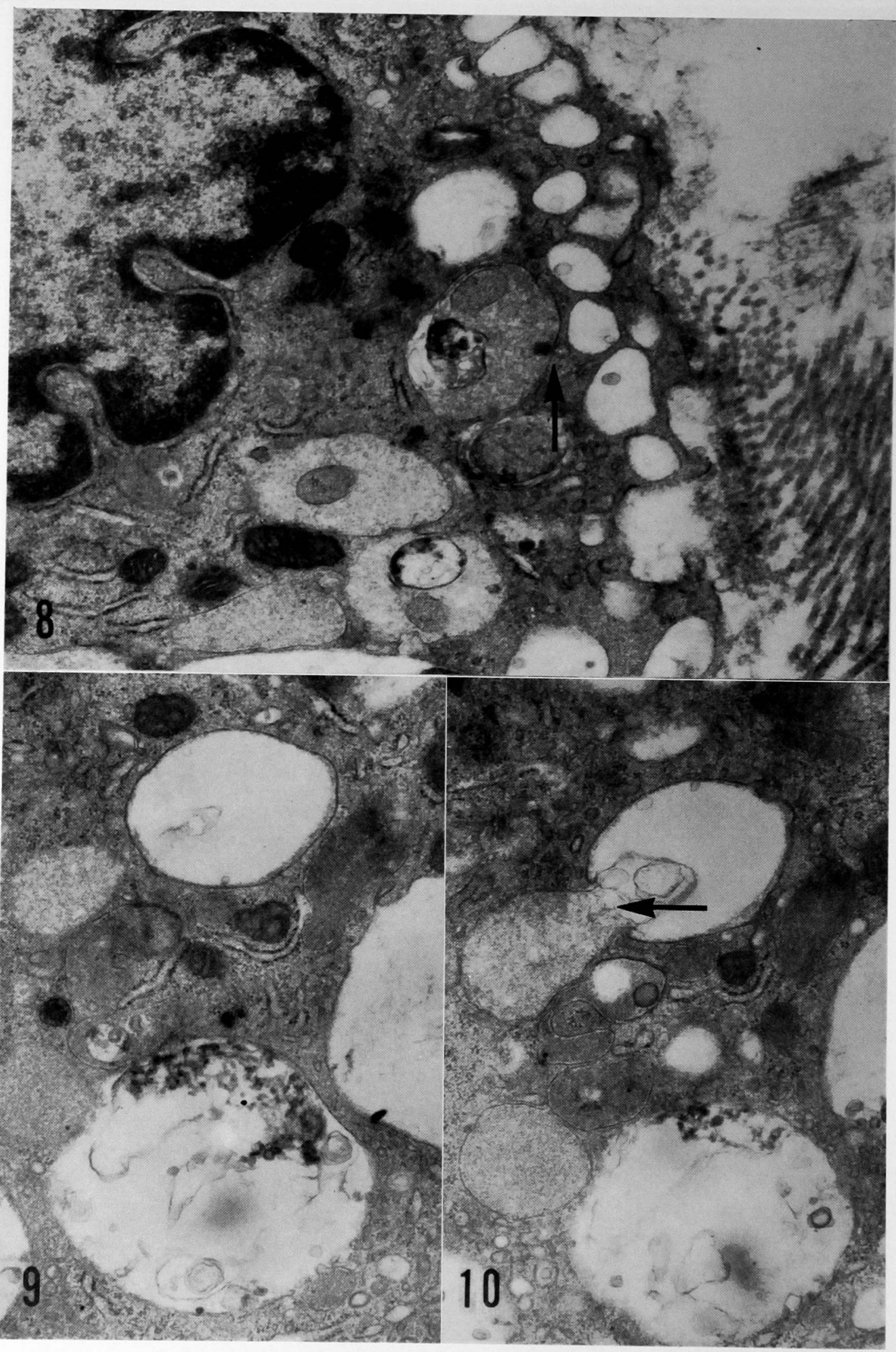


$\mathrm{S}-93$

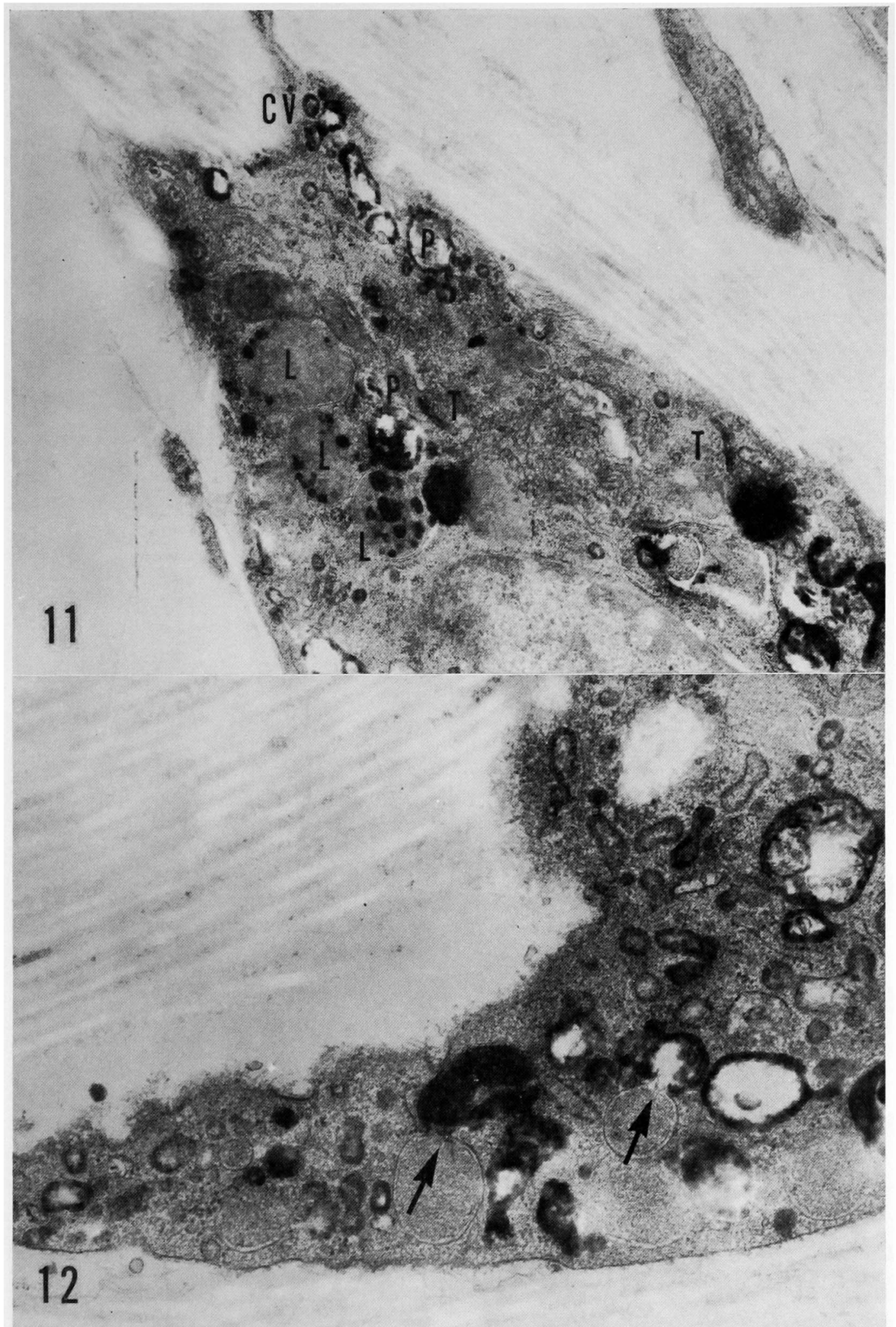

Supplement to J. Kansai Med. Sch., Vol. 24, March 1972 
$S-94$

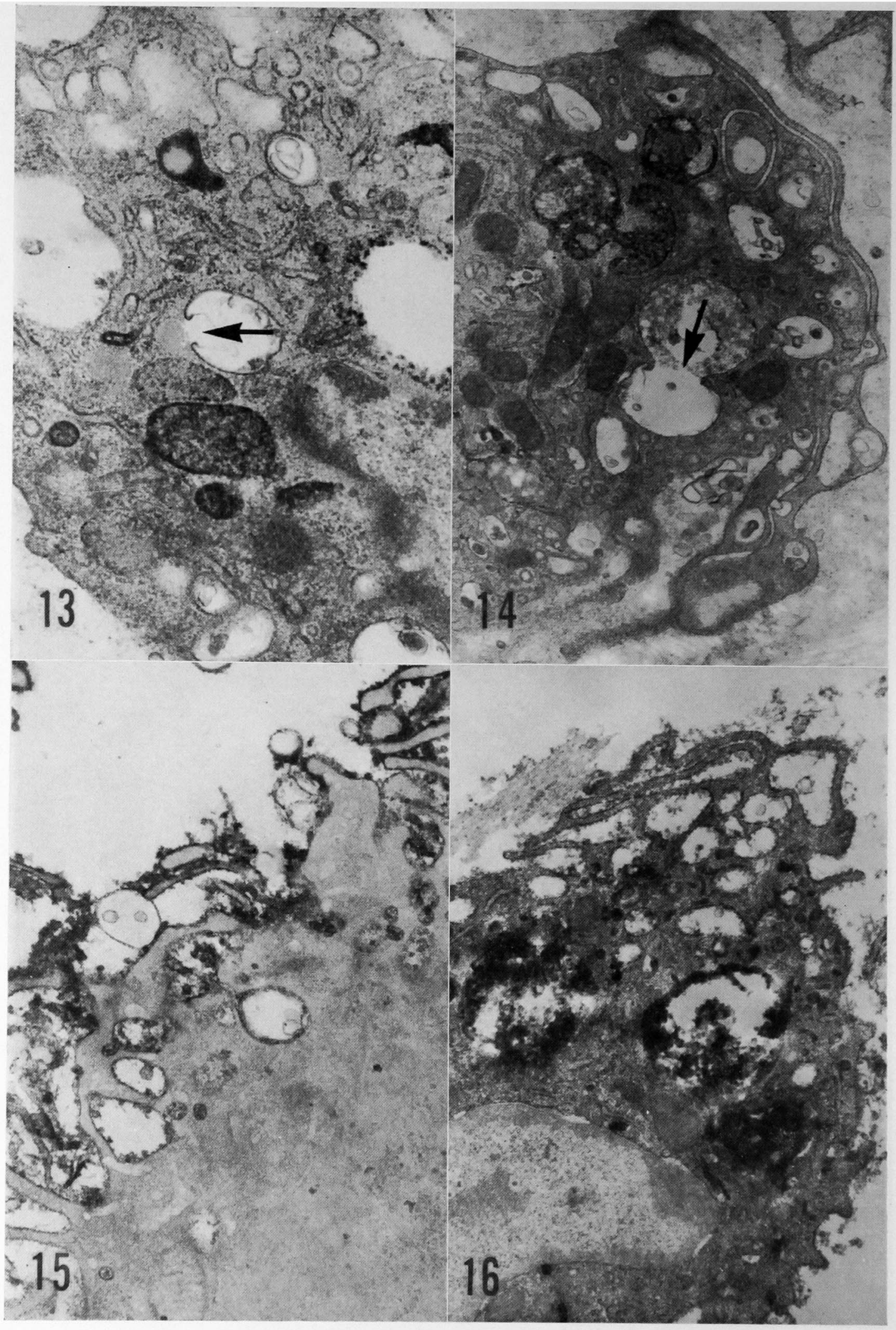




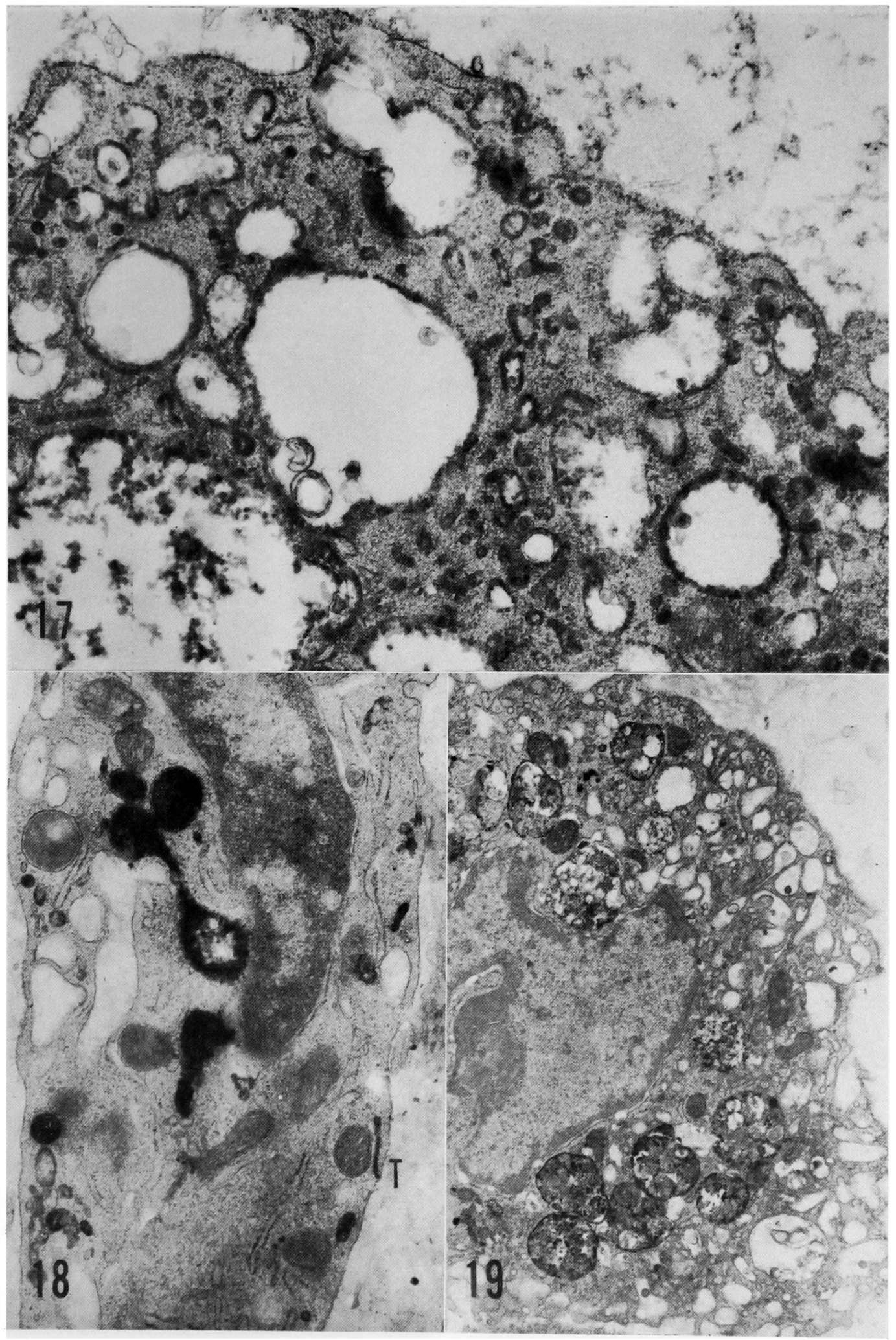

Supplement to J. Kansai Med. Sch., Vốl. 24, March 1972 
S -96

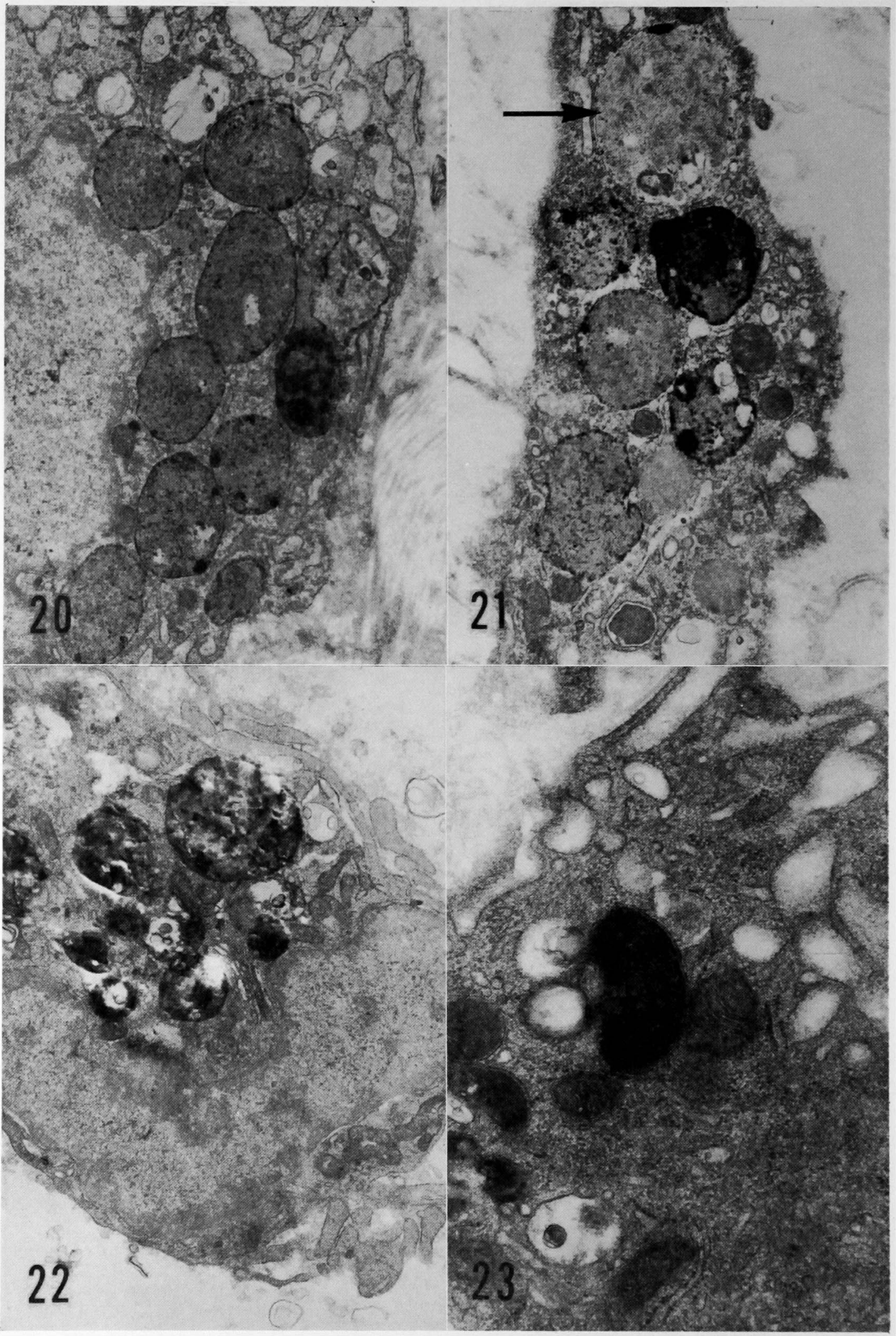




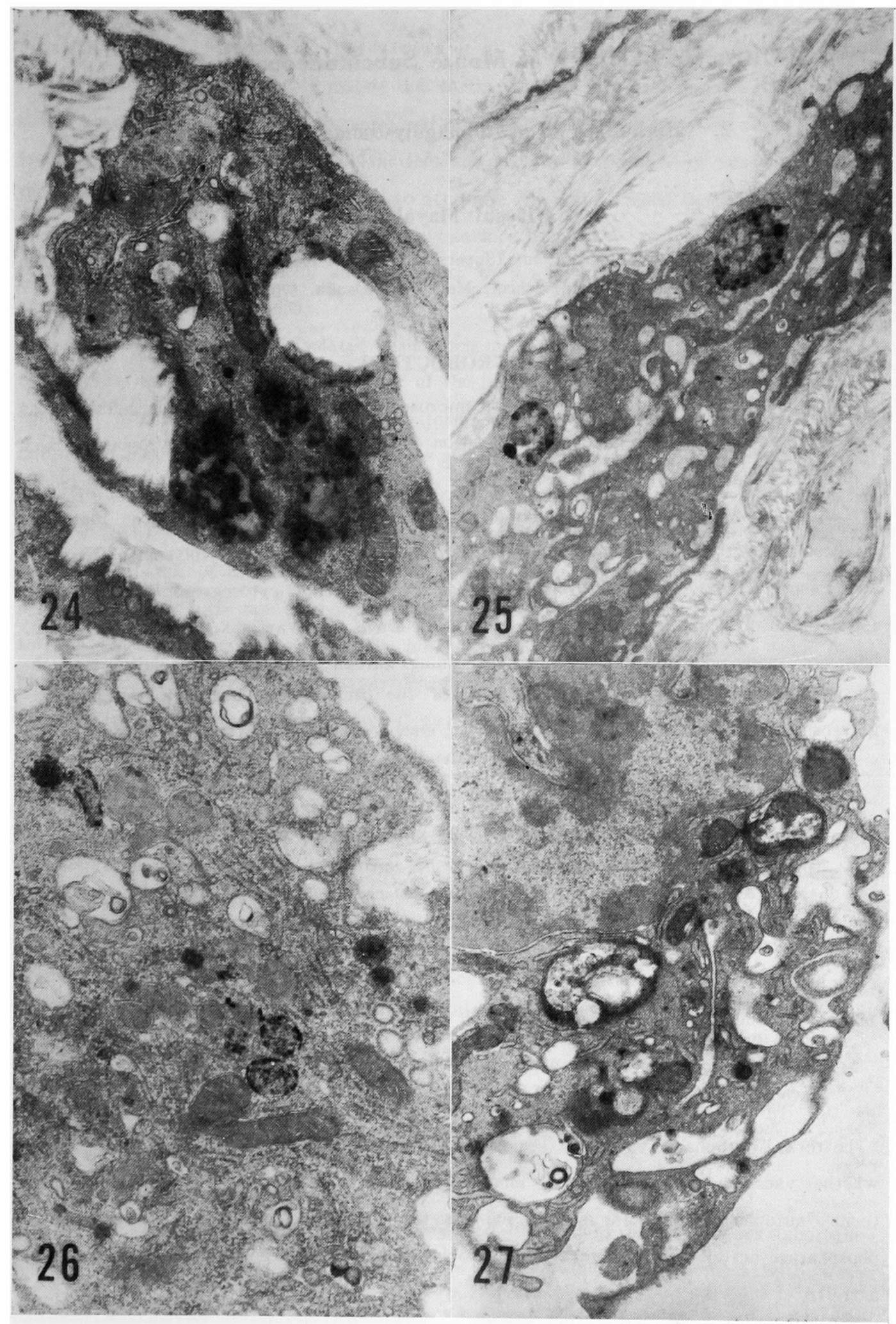

Supplement to J. Kansai Med. Sch., Vol. 24, March 1972 